\title{
Mitochondrial D310 mutation as clonal marker for solid tumors
}

\author{
Willemina R. R. Geurts-Giele ${ }^{1}$ - Gerard H. G. K. Gathier ${ }^{1,2}$ • Peggy N. Atmodimedjo ${ }^{1}$ • \\ Hendrikus J. Dubbink ${ }^{1} \cdot$ Winand N. M. Dinjens ${ }^{1}$
}

Received: 30 December 2014 / Revised: 17 June 2015 / Accepted: 20 July 2015 / Published online: 15 August 2015

(C) The Author(s) 2015. This article is published with open access at Springerlink.com

\begin{abstract}
Patients with multiple tumors, either synchronous or metachronous, can have metastatic disease or suffer from multiple independent primary tumors. While proper diagnosis of these patients is important for prognosis and treatment, this can be challenging using only clinical and histological criteria. The aim of the present study was to evaluate the value of mitochondrial D310 mutation analysis in diagnostic questions regarding tumor clonality for a wide range of tumor types. Sanger sequencing of D310 was performed on a diagnostic cohort of 382 patients with 857 tumors that were previously analyzed using routine molecular analysis on genomic DNA. The D310 mononucleotide repeat was frequently somatically mutated (56/321, $17 \%$ ) in several tumor types, including breast, head and neck, gynecological, lung, colorectal, and skin tumors. For $84 / 327$ (26\%) patients, a D310 mutation was detected in at least one of their tumors; for these patients, D310 can be used to determine the clonal relationship between their multiple tumors. Clonality assessments based on mitochondrial DNA (mtDNA) and routine genomic DNA analysis were concordant in 52/73 (71 \%) patients. We conclude that D310 mutation status might aid in determining clonality of clinically challenging synchronous or metachronous tumors. To this end, next generation
\end{abstract}

Electronic supplementary material The online version of this article (doi:10.1007/s00428-015-1817-5) contains supplementary material, which is available to authorized users.

Willemina R. R. Geurts-Giele

w.geurts-giele@erasmusmc.nl

1 Department of Pathology, Erasmus MC Cancer Institute, University Medical Center Rotterdam, P.O. Box 2040, 3000

CA Rotterdam, The Netherlands

2 Present address: Service XS, Plesmanlaan 1D, 2333 BZ Leiden, The Netherlands sequencing targeted genomic DNA assays should be complemented with mtDNA markers, such as the D310 repeat.

Keywords Mitochondrial DNA · Tumor clonality · Synchronous tumors $\cdot$ Metachronous tumors

\section{Introduction}

When a patient presents with multiple tumors, either synchronous or metachronous, the question arises whether this is metastatic (recurrent) disease or, alternatively, the patient suffers from multiple primary tumors, as appears to be the case in $8 \%$ of cancer patients [1]. To distinguish between multiple independent primary tumors and metastatic disease is of prime importance for prognosis and treatment [2] but can be challenging, when only clinical and histological criteria are available. Since tumor cells differ from normal cells by the presence of clonal DNA aberrations, these can be used to determine whether or not a clonal relationship exists between multiple tumors within one patient [2-4].

Most molecular clonality assays focus on genomic DNA. Human cells, however, also contain numerous copies of mitochondrial DNA (mtDNA). Mutations in mtDNA initially result in heteroplasmic cells (cells with mutant and nonmutant mitochondrial DNA molecules). Upon cellular expansion, these heteroplasmic cells can achieve mutant DNA homoplasmy (all mtDNA molecules within one cell harbor the same mutation), as has been demonstrated in tumor models, human tumors, and tumor cell lines [5-8]. Apparently, homoplasmic mtDNA aberrations have been frequently found in human tumors [9], notably in a polymorphic cytosine mononucleotide repeat within the non-coding displacementloop (D-loop) region (D310) [10]. In several studies on different tumor types, mitochondrial DNA alterations have been 
used as a marker for clonality [11-14]. The aim of the present study was to evaluate for a wide range of tumor types whether or not D310 mutation analysis helps to solve diagnostic questions regarding tumor clonality.

For this study, we selected patients with multiple synchronous or metachronous tumors, for which the question of a clonal relationship was raised leading to routine molecular analysis on genomic DNA. We addressed the following questions: (1) Do these tumors have mtDNA D310 mutations? (2) Are the tumors clonally related based on mtDNA analysis and does this correspond to the clonality status assessed by routine genomic DNA analysis?

\section{Materials and methods}

We studied a cohort of patients with synchronous or metachronous tumors for which routine molecular clonality analysis on genomic DNA had been performed between January 2006 and April 2013 at the Erasmus Medical Center, Rotterdam, The Netherlands. All cases concerned patients for which pathologists or clinicians had previously submitted a request for molecular analysis in view of questions regarding diagnosis, prognosis, and/or patient treatment. For routine analysis, normal and tumor DNA had been extracted from formalin-fixed paraffin-embedded (FFPE) tissue blocks using proteinase $\mathrm{K}$ and, for extractions from 2009 onwards, $5 \%$ Chelex 100 resin, as previously described [15]. DNA was used in accordance with the Code of Proper Use established by the Dutch Federation of Medical Scientific Societies (https:// www.federa.org/sites/default/files/digital_version_first_part code_of_conduct_in_uk_2011_12092012.pdf). On these tumors, depending on the amount of tissue available and the tumor type, different combinations of routine molecular analyses had been performed, among which loss of heterozygosity (LOH) analysis, TP53 mutation analysis following abnormal P53 immunohistochemical staining, and/or mutation analysis for other genes.

Of 466 patients eligible for inclusion in the study, 63 were excluded because no archival normal or tumor DNA was available, 17 because the original report was unavailable, and 4 because this was incomplete. In total, 857 tumors from 382 patients were included. Online Resource 1 shows an overview of all tumor details. Consecutive tumors in any single patient included have been numbered $\mathrm{T} 1$ to $\mathrm{T} 7$, in chronological order with $\mathrm{T} 1$ being the first diagnosed; in most cases this was the primary tumor.

PCR amplification of D310 was performed with normal and tumor DNA using Kapa 2G robust hotstart readymix (Kapa Biosystems, Woburn, MA) and M13-tailed custom-made primers (forward TGT AAA ACG ACG GCC AGT - TTG AAT GTC TGC ACA GCC AC and reverse CAG GAA ACA GCT ATG ACC - GGG GTT TGG CAG AGA TGT
G). After purification using Exonuclease I and FastAP Thermosensitive Alkaline Phosphatase (Fermentas, Thermo Fisher Scientific, Waltham, MA), PCR products were sequenced with M13 primers using the BigDye Terminator v3.1 kit (Applied Biosystems, Foster City, CA). Fragments were detected on a ABI 3730xl genetic analyzer (Applied Biosystems). D310 repeat length (nucleotide position 303-309) was evaluated by visual inspection using Mutation Surveyor v.3.24 software (SoftGenetics, State College, PA). An altered D310 repeat length in tumor DNA compared to patient-matched normal DNA was classified as a D310 mutation (either deletion or insertion). To exclude genomic DNA amplification, DNA isolated from mtDNA-less cells was used as a negative control (143B/206 $\rho 0$, a kind gift of Dr. G.P. Comi, Dino Ferrari Centre, Neuroscience Section, Department of Pathophysiology and Transplantation (DEPT), University of Milan, Milan, Italy).

\section{Results}

Detailed results on the analysis of D310 in 857 synchronous or metachronous tumors of 382 patients are shown in Online Resource 1. Corresponding normal DNA could be evaluated in 332 patients and showed D310 repeat lengths of $6,7,8$, or 9 cytosines (for 1, 187, 123, and 21 patients, respectively). Both normal DNA and DNA from the first tumor (T1) could be evaluated in 321 patients. A D310 mutation was found in $56 / 321(17 \%)$ of $\mathrm{T} 1$, of which $11 / 85(13 \%)$ in breast, $11 / 62$ $(18 \%)$ in head and neck, 4/35 (11\%) in gynecological, 5/26 (19\%) in lung, 8/25 (32\%) in colorectal, and 3/19 (16\%) in skin tumors (Fig. 1). In 35/56 (63\%) tumors, an insertion of 1 , 2 , or 3 nucleotides was found (in 25, 7, and 3 tumors, respectively); $21 / 56(37 \%)$ tumors showed a deletion of 1,2 , or multiple nucleotides (18, 2, and 1 tumors, respectively).

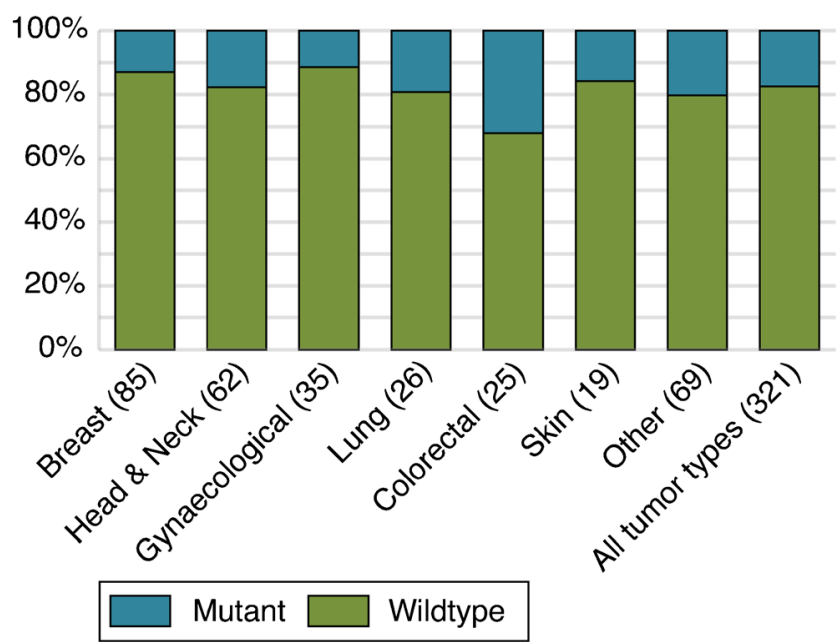

Fig. 1 Percentage of D310 mutations in the chronologically first diagnosed tumors of all patients. The tumors are categorized by tumor type; after each tumor type, the number of tumors with an evaluable result is shown between parentheses 


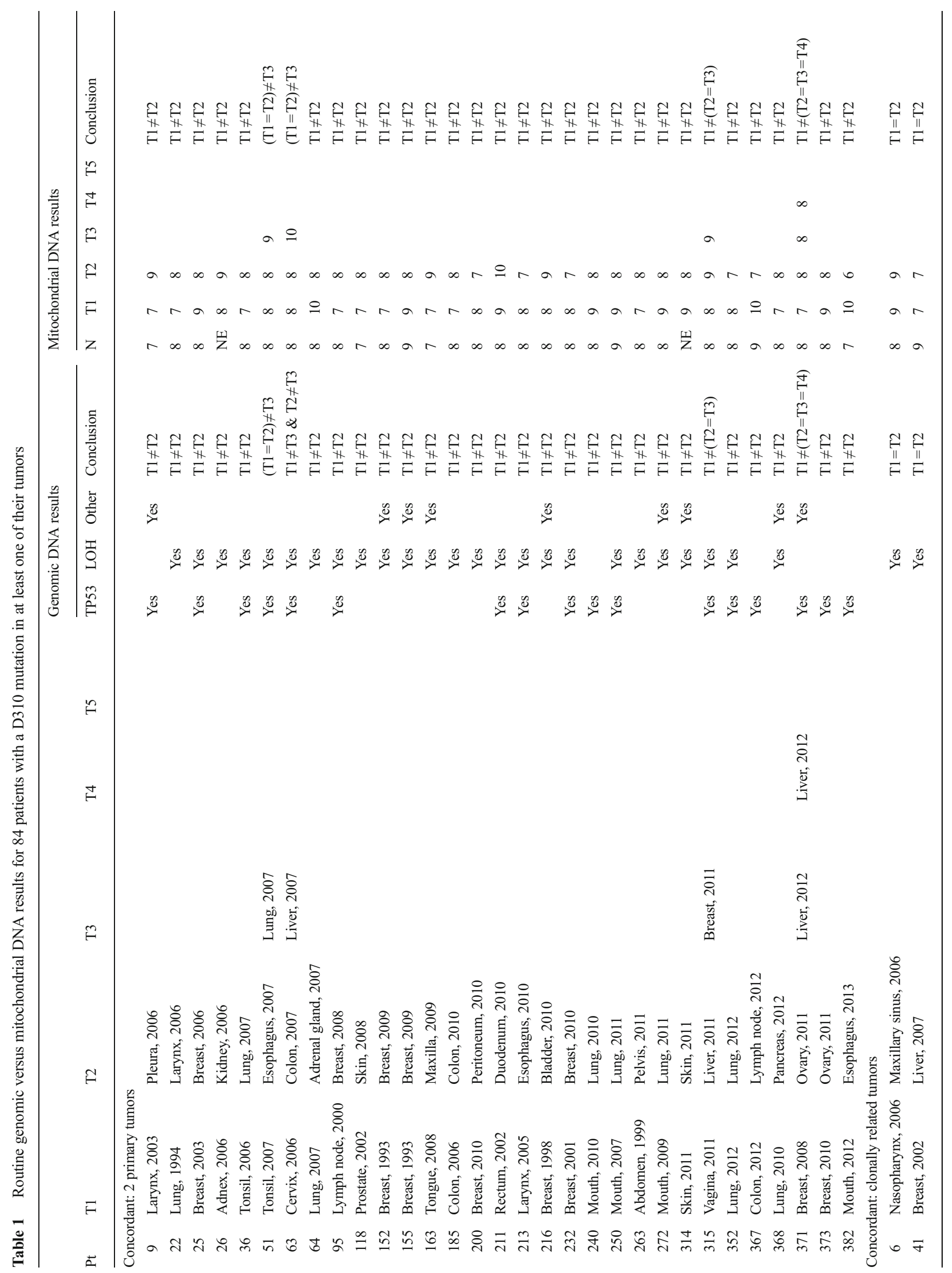




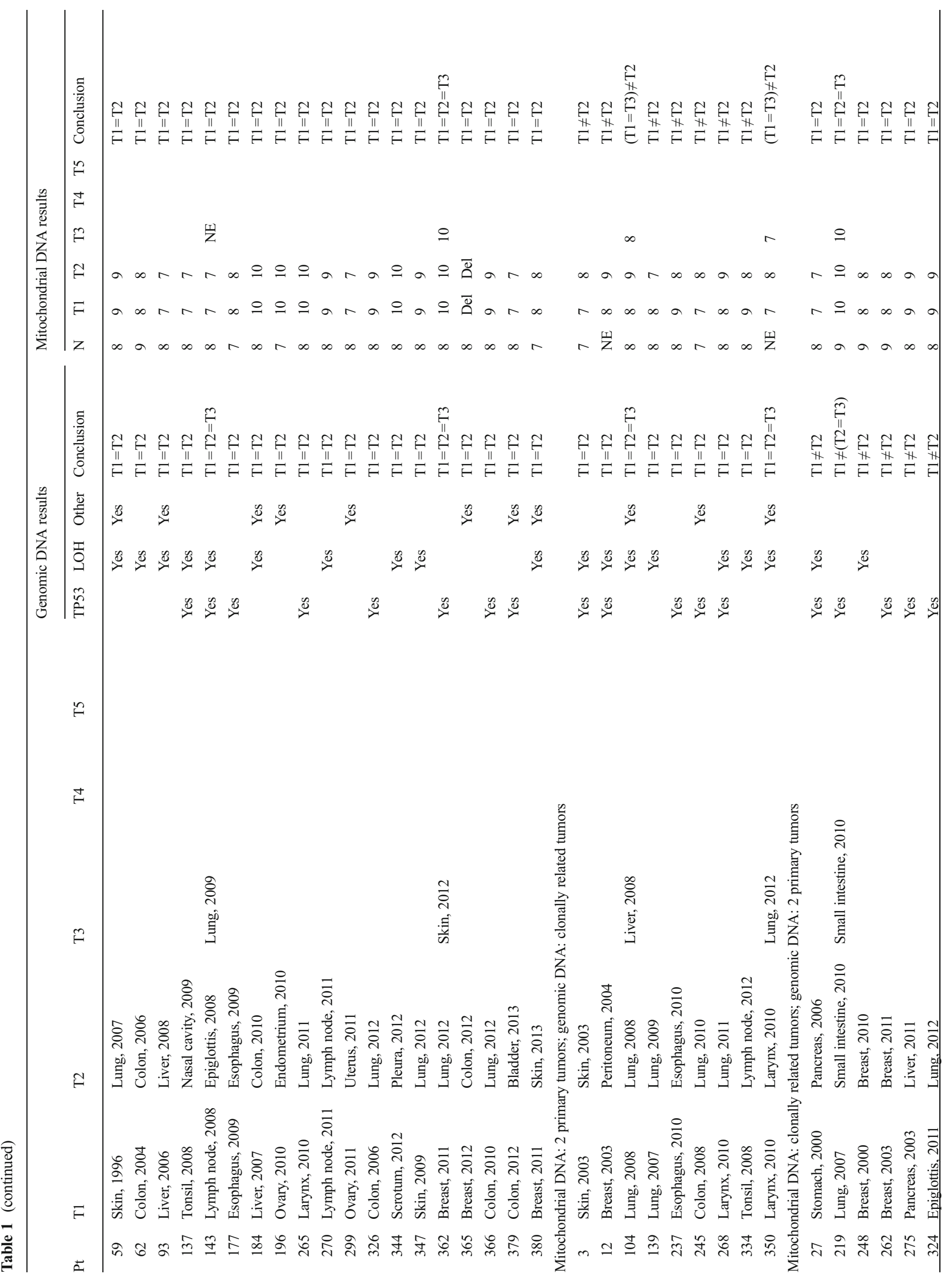




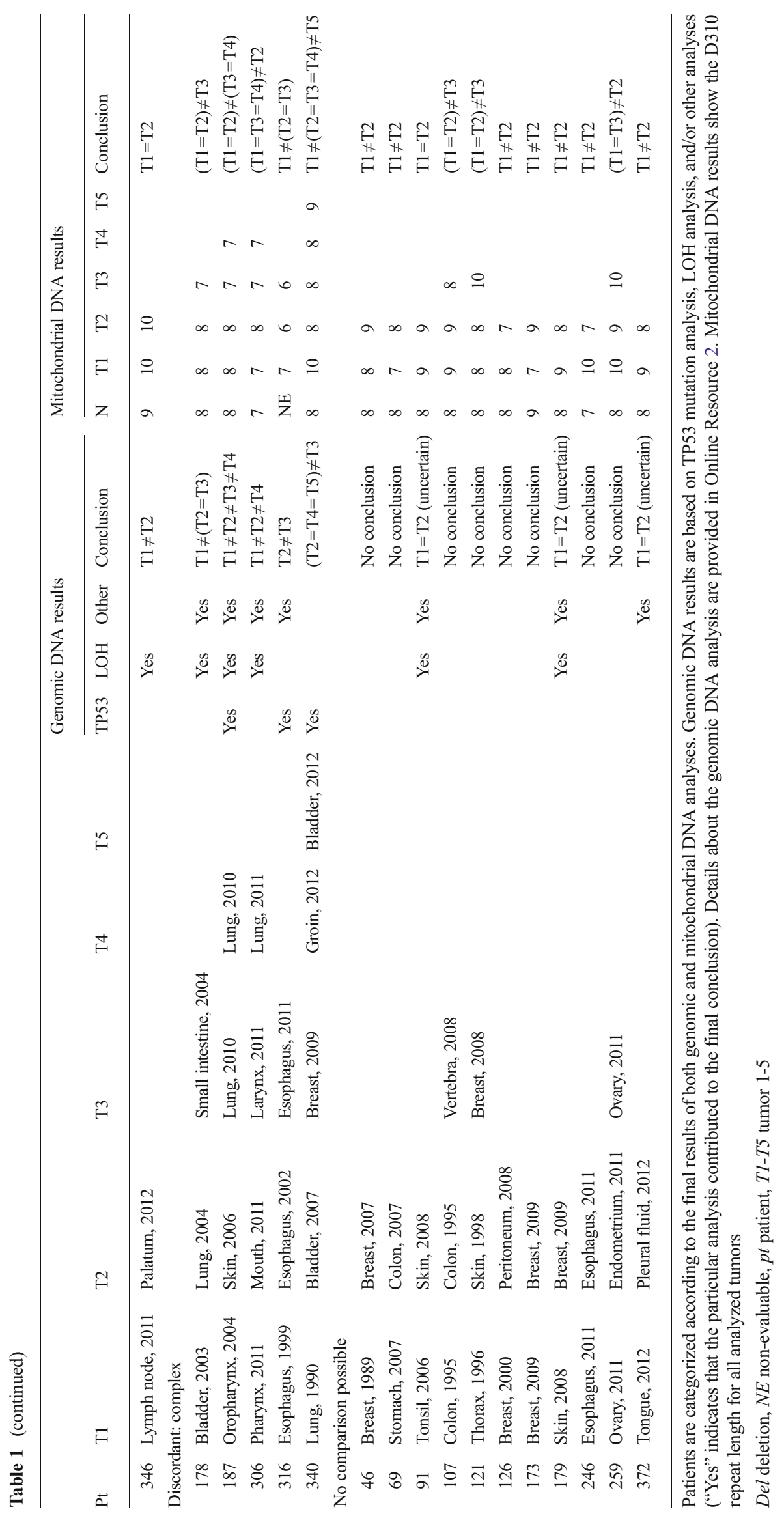




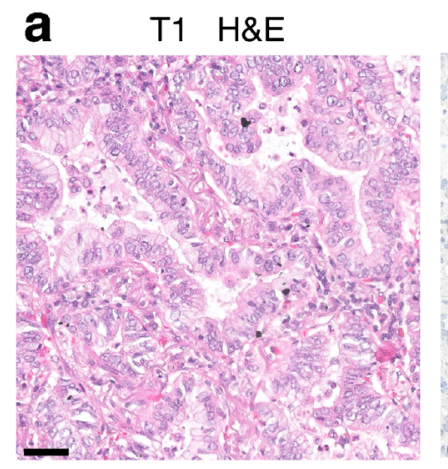

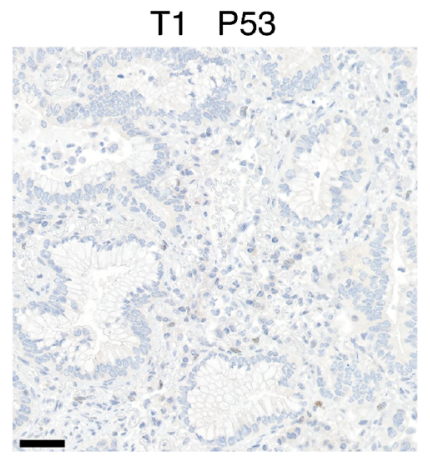

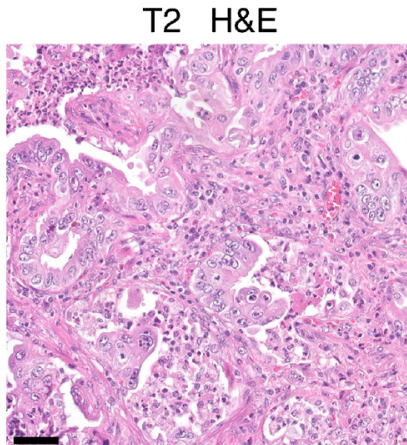

T2 P53

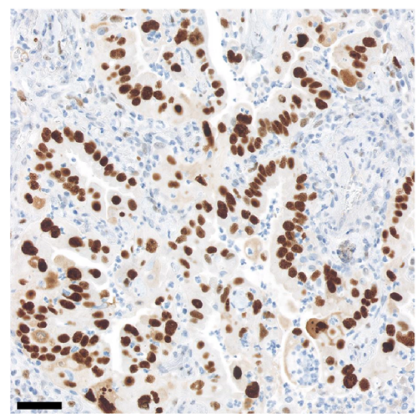

b $\quad$ D17S786

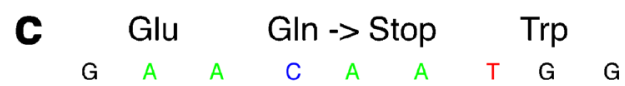
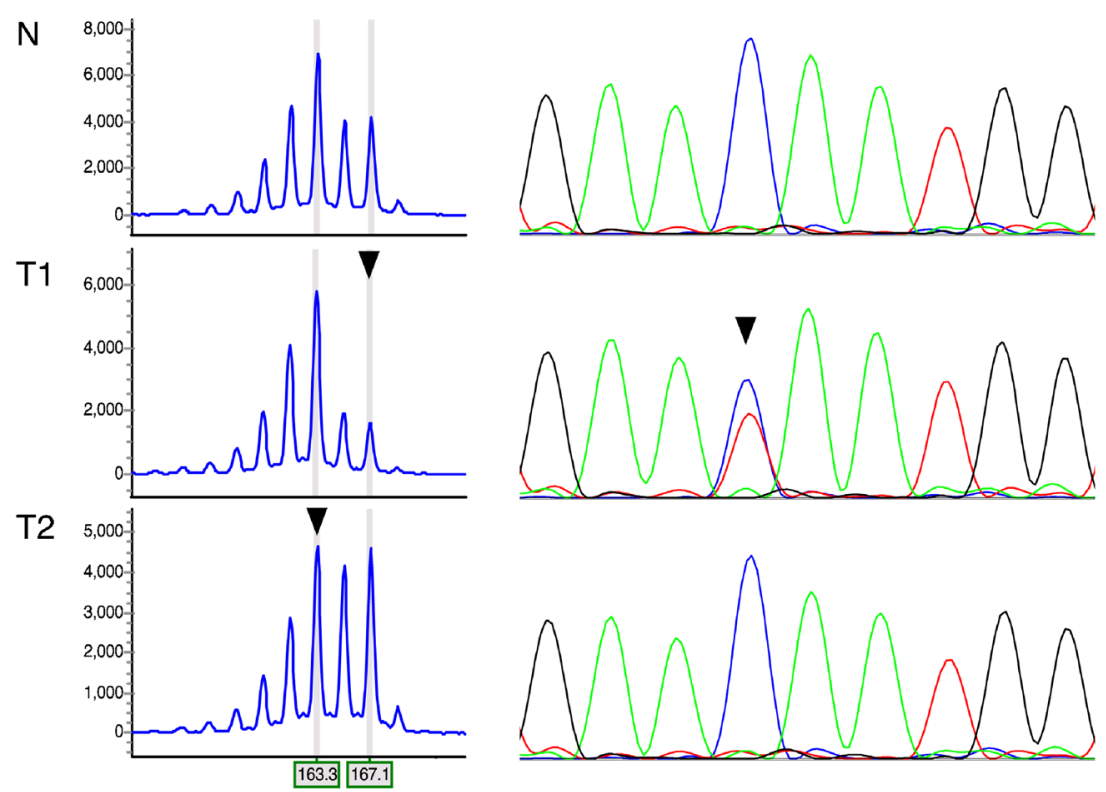

T2
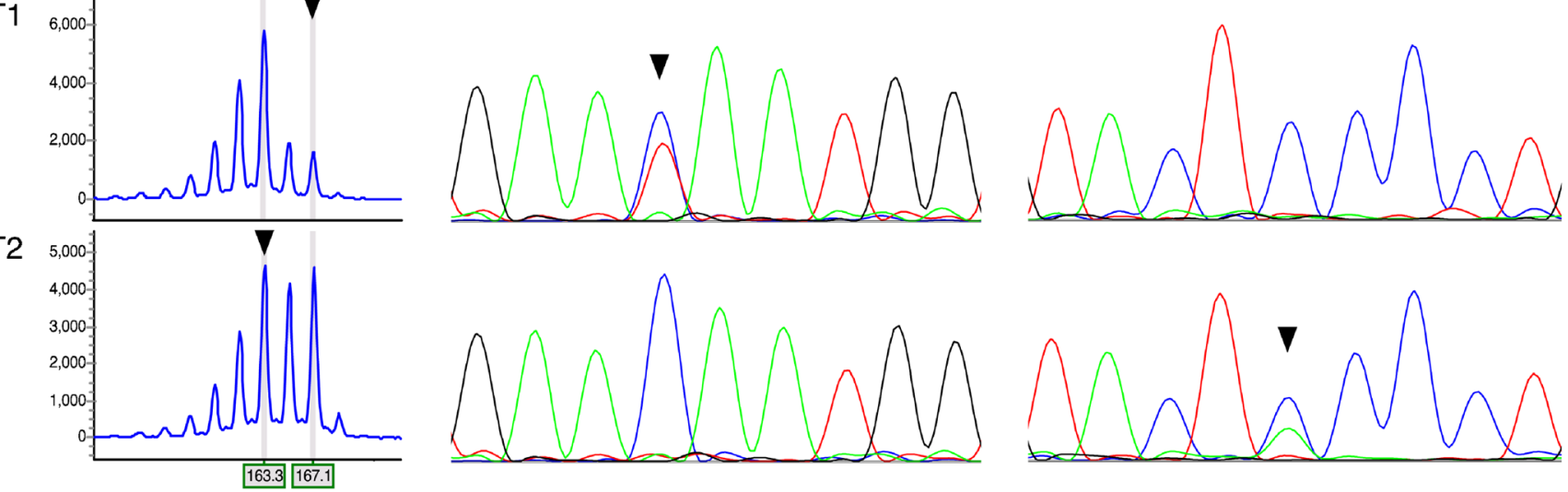

d
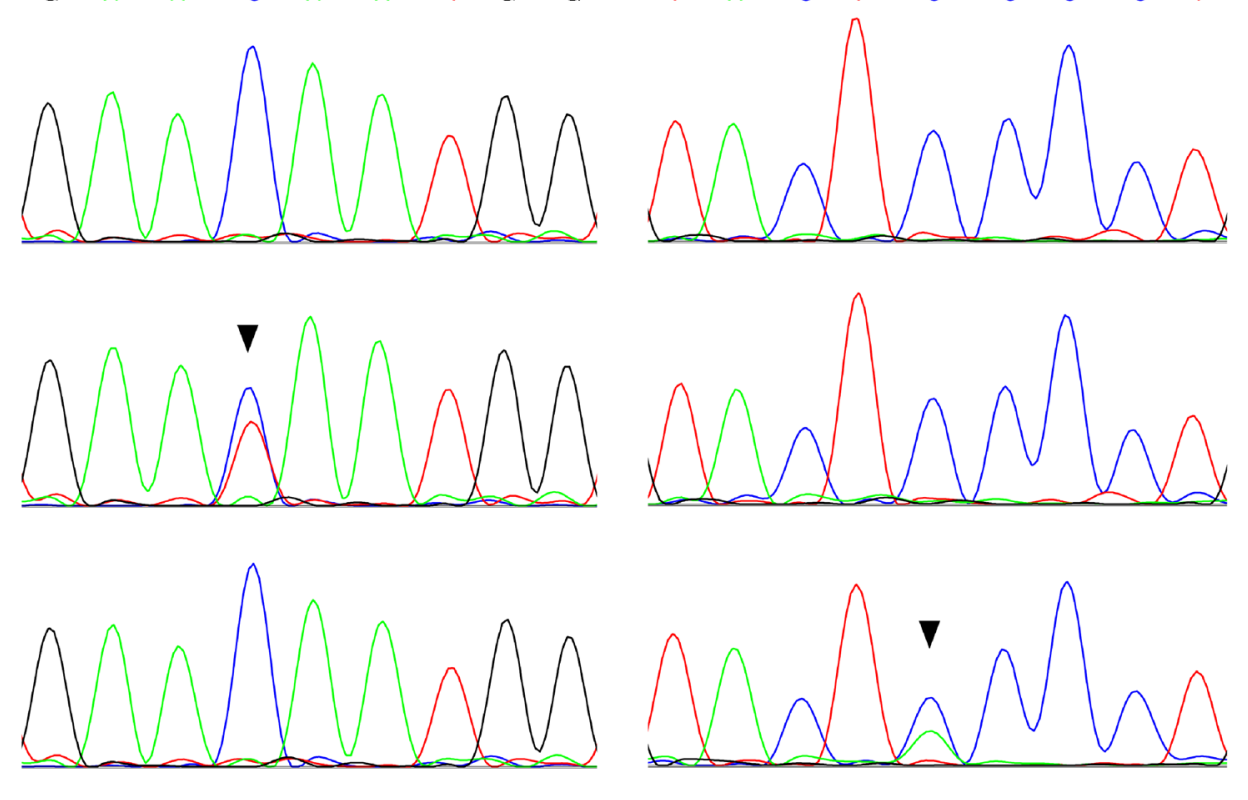

D310

$\mathrm{N}$

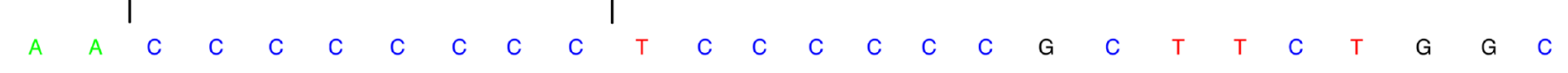

西

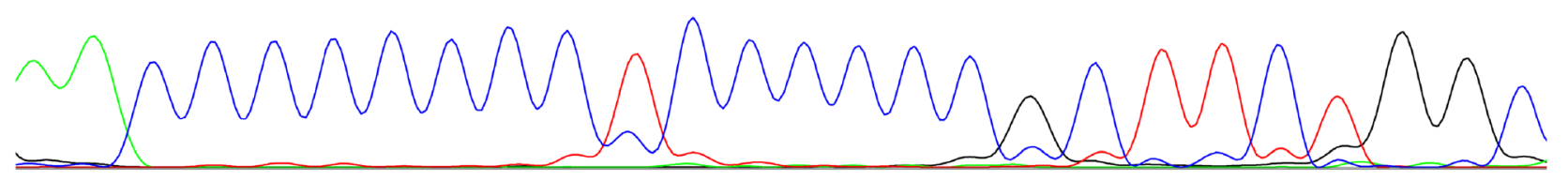

T1

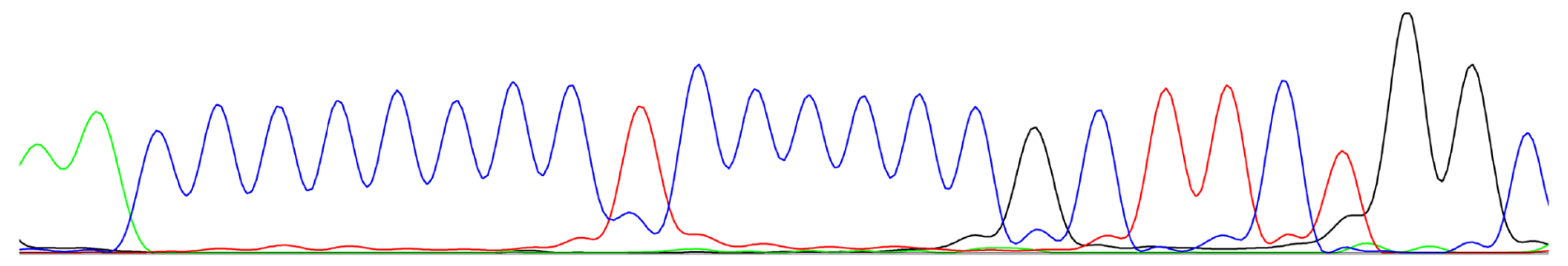

T2

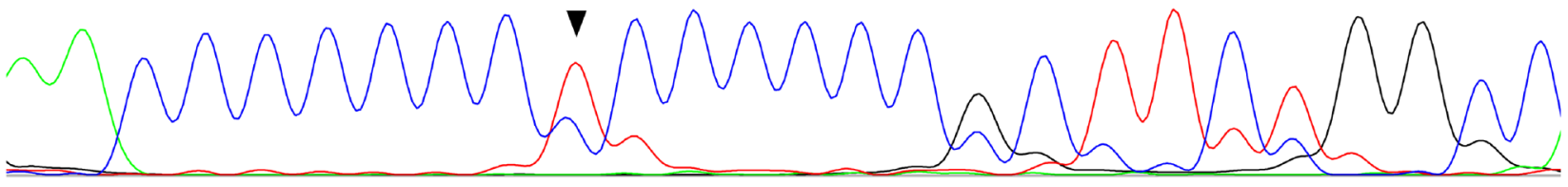


4 Fig. 2 Routine genomic DNA and mitochondrial DNA results for patient 352, whom was diagnosed with synchronous tumors of the right (T1) and the left lung (T2). a Both tumors were diagnosed as adenocarcinomas with a bronchioloalveolar growth pattern; T1 shows absence of P53 staining, whereas T2 shows clear nuclear P53 staining. Scale bars represent $50 \mu \mathrm{m}$. b Routine genomic DNA analysis was performed on DNA isolated from normal $(N)$ and both tumor tissues (T1 and T2). LOH analysis of marker D17S786 (TP53) showed loss of the large allele in $\mathrm{T} 1$ and loss of the small allele in T2, indicated by arrowheads. The horizontal axis indicates the size of the DNA fragments in basepair; the vertical axis indicates signal intensity. c Routine Sanger sequencing of TP53 showed a p.Gln52* mutation only in T1, and a p.Ser127Tyr mutation only in T2, both indicated by arrowheads. d Sanger sequencing of mitochondrial DNA marker D310 showed an 8-cytosine repeat in normal DNA, no aberrations in T1, and a 1 -bp deletion in T2, as indicated by the arrowhead. The results of routine genomic DNA and mitochondrial DNA analysis both indicate that T1 and $\mathrm{T} 2$ represent two primary tumors. $H \& E$ hematoxylin and eosin stain

Of the 327 patients for whom D310 status could be determined, 243 (74\%) showed tumors without D310 aberrations, while in $84(26 \%)$ a D310 mutation was detected in one or more tumors (Table 1). Of the 84 patients with a D310 mutated tumor, $29(35 \%)$ had clonally related tumors and $55(65 \%)$ had multiple primary tumors based upon D310 mutation status. For 73 of these 84 patients, a final clonality status assessed by genomic DNA molecular clonality analysis was available, and in 52 (71\%), mtDNA and genomic DNA results were concordant (Figs. 2 and 3; Online Resource 2).

\section{Discussion}

We found that the D310 mononucleotide repeat in mtDNA is somatically mutated in $13 \%$ of breast tumors, $18 \%$ of head and neck tumors, $11 \%$ of gynecological tumors, $19 \%$ of lung tumors, $32 \%$ of colorectal tumors, and $16 \%$ of skin tumors. These results are in close agreement with previous studies in which D310 mutations were found in 11-28\% of breast tumors, $0-16 \%$ of head and neck tumors, 3-26\% of ovarian tumors, $0-13 \%$ of lung tumors, and $8-36 \%$ of colon tumors [10].

The identified D310 mutations were (nearly) homoplasmic, indicating that these mutations are present in the majority of

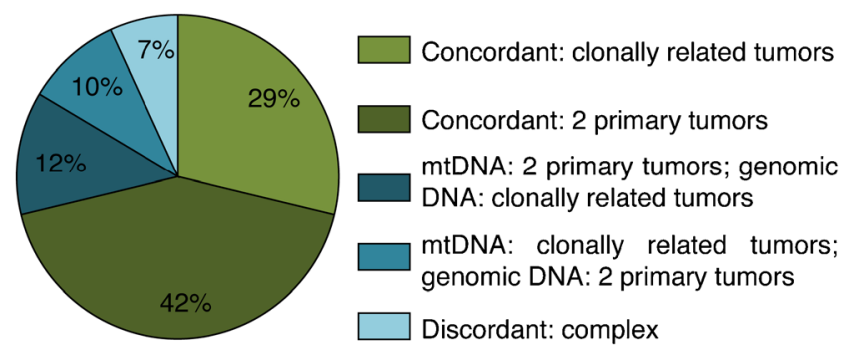

Fig. 3 Clonality status assessed by mitochondrial DNA (mtDNA) results compared to routine genomic DNA results for 73 patients with a D310 mutation in one or more of their tumors the neoplastic cells and as a consequence must have occurred early during oncogenesis. Heteroplasmic D310 mutations have been reported in normal cells, achieving homoplasmy in tumor cells $[6,12]$. This suggests that D310 mutation status might provide an ideal marker for tumor clonality. We found in 84/327 (26\%) patients with synchronous or metachronous tumors, for which the question of a clonal relationship was raised, a D310 mutation in at least one of the tumors. In such cases, D310 mutation status can be used to determine the possible clonal relationship between the tumors. In a large majority of patients (71\%), clonality status assessed by mtDNA analysis and routine genomic DNA analysis were concordant.

Discordant results between clonality status assessed by mtDNA and genomic DNA analysis were found in 21/73 (29 \%) patients. Clonality assays on multiple tumors often result in some markers with concordant results but also markers with discordant results between the different tumors. Close scrutiny of individual markers is then necessary to decide whether the tumors are clonally related or not in view of the notion that genomic DNA analysis generates a likelihood that multiple tumors might be clonally related, but does not provide a definitive result. For 11 of our patients with discordant results, a highly likely diagnostic result was obtained because the tumors had a mutation in common, had mutually exclusive mutations, or the first tumor had a mutation that was not found in consecutive tumor(s). For these patients, the discordant mtDNA result was probably incorrect. Possible explanations are firstly that two primary tumors by chance may have acquired identical D310 mutations, secondly that de novo D310 mutations acquired during tumor progression result in clonally related tumors with different D310 mutations, and thirdly that intercellular or intracellular heterogeneity (heteroplasmy) in regard of D310 mutations is maintained during tumor development. For five patients, a likely diagnostic result was obtained because a mutation was only present in a consecutive tumor or the tumors showed common or different LOH status of five or more loci. For another five patients, the diagnostic result was weak, based on common or different LOH status of less than five loci. To reliably classify such tumors as clonally related or not, more informative genomic and/or mtDNA markers would be necessary.

Although D310 mutations are the most common mtDNA mutations in human cancer, other mtDNA deletions, insertions, and point mutations have been described [9]. Recently, next generation sequencing assays for mitochondrial DNA have become available [16]. The use of such assays for clonality analysis would result in the detection of more mutations and probably result in a higher predictive value. However, approximately 1.8 point mutations in somatic mtDNA have been found in only $60 \%$ of cancers [9], emphasizing the necessity to include analysis of genomic DNA as well. Mitochondrial DNA markers 
might be helpful when only a small number of cells are available, in view of the high number of mtDNA copies per cell compared to genomic DNA.

This study also has some limitations. Even though mtDNA is present in numerous copies per cell, facilitating amplification and analysis of a minute number of cells, no or an ambiguous D310 mutation analysis result was obtained for 55/ $382(14 \%)$ patients. This was mostly due to an insufficient amount of DNA. For 11/84 (13\%) patients with D310 mutations, a final clonality status assessed by genomic DNA analysis was not available, and for these patients, we were unable to compare mtDNA with genomic DNA results.

We conclude that D310 mutation status might aid in clonality determinations of clinically challenging synchronous or metachronous tumors, but as a single assay, has limited predictive value. To further evaluate the potential contribution of mtDNA markers to assessment of tumor clonality, we propose to include in existing next generation sequencing targeted genomic DNA assays mtDNA markers, such as the D310 repeat.

Conflict of interest The authors declare that they have no conflicts of interest.

Open Access This article is distributed under the terms of the Creative Commons Attribution 4.0 International License (http:// creativecommons.org/licenses/by/4.0/), which permits unrestricted use, distribution, and reproduction in any medium, provided you give appropriate credit to the original author(s) and the source, provide a link to the Creative Commons license, and indicate if changes were made.

\section{References}

1. Mariotto AB, Rowland JH, Ries LA, Scoppa S, Feuer EJ (2007) Multiple cancer prevalence: a growing challenge in long-term survivorship. Cancer Epidemiol Biomarkers Prev 16:566-571

2. van der Sijp JR, van Meerbeeck JP, Maat AP, Zondervan PE, Sleddens HF, van Geel AN, Eggermont AM, Dinjens WN (2002) Determination of the molecular relationship between multiple tumors within one patient is of clinical importance. J Clin Oncol 20: $1105-1114$

3. Warth A, Macher-Goeppinger S, Muley T, Thomas M, Hoffmann H, Schnabel PA, Penzel R, Schirmacher P, Aulmann S (2012)
Clonality of multifocal nonsmall cell lung cancer: implications for staging and therapy. Eur Respir J 39:1437-1442

4. Ortiz BH, Ailawadi M, Colitti C, Muto MG, Deavers M, Silva EG, Berkowitz RS, Mok SC, Gershenson DM (2001) Second primary or recurrence? Comparative patterns of $\mathrm{p} 53$ and K-ras mutations suggest that serous borderline ovarian tumors and subsequent serous carcinomas are unrelated tumors. Cancer Res 61:7264-7267

5. Coller HA, Khrapko K, Bodyak ND, Nekhaeva E, Herrero-Jimenez P, Thilly WG (2001) High frequency of homoplasmic mitochondrial DNA mutations in human tumors can be explained without selection. Nat Genet 28:147-150

6. Sanchez-Cespedes M, Parrella P, Nomoto S, Cohen D, Xiao Y, Esteller M, Jeronimo C, Jordan RC, Nicol T, Koch WM, Schoenberg M, Mazzarelli P, Fazio VM, Sidransky D (2001) Identification of a mononucleotide repeat as a major target for mitochondrial DNA alterations in human tumors. Cancer Res 61: 7015-7019

7. Mambo E, Gao X, Cohen Y, Guo Z, Talalay P, Sidransky D (2003) Electrophile and oxidant damage of mitochondrial DNA leading to rapid evolution of homoplasmic mutations. Proc Natl Acad Sci U S A 100:1838-1843

8. Shidara Y, Yamagata K, Kanamori T, Nakano K, Kwong JQ, Manfredi G, Oda H, Ohta S (2005) Positive contribution of pathogenic mutations in the mitochondrial genome to the promotion of cancer by prevention from apoptosis. Cancer Res 65:1655-1663

9. Lee HC, Chang CM, Chi CW (2010) Somatic mutations of mitochondrial DNA in aging and cancer progression. Ageing Res Rev 9(Suppl 1):S47-S58

10. Lee HC, Wei YH (2009) Mitochondrial DNA instability and metabolic shift in human cancers. Int J Mol Sci 10:674-701

11. Giunti L, Bernini G, Forni M, Tucci F, Wheeler E, Sardi I (2006) Clonality analysis of pediatric multiple tumors: two case reports and laboratory investigation. J Pediatr Hematol Oncol 28:241-248

12. Nomoto S, Yamashita K, Koshikawa K, Nakao A, Sidransky D (2002) Mitochondrial D-loop mutations as clonal markers in multicentric hepatocellular carcinoma and plasma. Clin Cancer Res 8:481-487

13. Masuda S, Kadowaki T, Kumaki N, Tang X, Tokuda Y, Yoshimura S, Takekoshi S, Osamura RY (2012) Analysis of gene alterations of mitochondrial DNA D-loop regions to determine breast cancer clonality. Br J Cancer 107:2016-2023

14. Montebugnoli L, Leonardi E, Morandi L, Farnedi A, Gissi DB, Marchetti C, Tarsitano A, Balbi T, Gentile L, Cocchi R, Foschini MP (2014) Genetic relationship between multiple squamous cell carcinomas arising in the oral cavity. Head Neck 36:94-100

15. van Lier MG, Wagner A, van Leerdam ME, Biermann K, Kuipers EJ, Steyerberg EW, Dubbink HJ, Dinjens WN (2010) A review on the molecular diagnostics of Lynch syndrome: a central role for the pathology laboratory. J Cell Mol Med 14:181-197

16. Wong LJ (2013) Next generation molecular diagnosis of mitochondrial disorders. Mitochondrion 13:379-387 